\title{
Insect Repellent of Cellullosic Fabrics (A Review)
}

\author{
Ghada A. Elsayed ${ }^{1}$, Ahmed G. Hassabo 2,*iD \\ 1 Textile Printing, Dyeing and Finishing Department, Faculty of Applied Arts, Benha University, Benha, Egypt \\ 2 National Research Centre (Scopus affiliation ID 60014618), Textile Industries Research Division, Pretreatment, and \\ Finishing of Cellulose-based Textiles Department, 33 El-Behouth St. (former El-Tahrir str.), Dokki, P.O. 12622, Giza, \\ Egypt \\ * Correspondence: aga.hassabo@hotmail.com;
}

Scopus Author ID 55909104700

Received: 31.03.2021; Revised: 16.05.2021; Accepted: 20.05.2021; Published: 27.06.2021

\begin{abstract}
Day after day, the risk of contracting diseases caused by mosquitoes increased, so studying how to avoid mosquito bites was of great importance. This is done by using a mosquito repellent directly on the skin or applying it to textiles, which are chemicals or natural substances that affect mosquitoes by inhibiting and repelling them. This material is applied by the microencapsulation method, cyclodextrin applications, emulsion, or direct application method.
\end{abstract}

Keywords: insect; mosquito; repellent; natural fibers.

(c) 2021 by the authors. This article is an open-access article distributed under the terms and conditions of the Creative Commons Attribution (CC BY) license (https://creativecommons.org/licenses/by/4.0/).

\section{Introduction}

Cotton, flax, jute, ramie, and sisal are natural vegetable polymeric cellulose fibers [13]. They are excellent natural materials that have been widely used in many fields, especially in the textile industry. These fabrics have good water ability, softness, hygroscopicity, natural durability, and less electricity. It can also be processed to give it a wide variety of colors due to its ability to be dyed in multiple ways, and It would be beneficial to impart high-performance properties to natural fibers to functionalize the natural fibers absorption and/or penetration of functional polymeric materials onto/into the fiber surface [4-12].

Insect bites have harmful effects, irritation and illness. The less severe effect is a simple irritation, swelling, and pain that sometimes come from bites by insects such as mosquitoes. These bites can become irritated, and the locations of the bites may become red and swollen in some instances [13]. Due to the infectious diseases transmitted by mosquitoes, hundreds of thousands of people die every year, and malaria is one of those diseases. By ongoing study and discovery of global scientific Researchers, mosquito-repellent textiles have been found and research is being conducted to develop them $[14,15]$.

Repellents have an important role to play in different anti-mosquito products, while not quite used, they are essential raw materials for the manufacture of different anti-mosquito products [14]. Protection from a mosquito can be achieved by applying insect repellent like N, N-diethyl-meta-toluamide (DEET) directly on the skin or in combination with textile containing permethrin [16]. 


\section{Mechanism of Repellent Action}

Carbon dioxide, lactic acid, skin temperature, and moisture are among the most important mosquito attractants. Insects use warm and humid convection rising from the human body as a guide for approaching humans. The action of mosquito repellents can be broadly divided into two categories-action on their olfactory senses and action on their tactile senses. The repellent's function is called transpiration repelling. It stops the insects from reaching a surface treated with the repellent [16]. The repellent molecules block the humidity sensory holes of the insects, making humans inaccessible to insects by inhibiting the function of sensing moisture. The action of the repellent stimulating sense of touch is called direct contact repelling and this drives insects off the processed surface before bloodsucking, even after touching the surface. It is believed that repellent substances work on the peripheral nervous systems of insects $[17,18]$. When contact is made, it causes a collaterally expressed confusional state and inhibition under sublethal doses before knockdown and lethal action. Thus, understanding how insect repellents work and how these chemicals interact with odors will allow the design of potential combinations that interfere with insects' sensory signals and ultimately disrupt their perceptual processes. Several chemicals have proven that mosquitoes are repelled [16].

\section{Types of Insect Repellent Finishes}

\subsection{Synthetic Repellents.}

\subsubsection{DEET.}

DEET (Figure 1) is a slightly yellow oil and is the most common active ingredient in many insect repellent products. Products containing it currently are available to the public in various liquids, lotions, sprays, and impregnated materials [16,19]. It is intended to be applied on the skin or clothing and protects against mosquitoes. However, more recent evidence shows that DEET serves as a true repellent in that mosquitoes dislike the smell of this chemical $[16,19$ 21]. DEET showed a strong repellent activity in the absence of body odor attractants in a behavioral test. Even though it's considered the most widely used mosquito repellent, it seems to have some health risks and isn't recommended for children under two minutes months of age, while we should exercise caution with it, especially the children and pregnant women [16].

\subsubsection{Picaridin.}

Picaridin [1-piperidinecarboxylic acid 2-(2-hydroxyethyl)-1-methylation-lester] (Figure 1) is one of insect repellent effective against mosquitoes which is similar in efficacy to DEET but more pleasant to use and much less likely to be a dermal irritant $[16,19]$. The actual mechanism of action of picaridin is unclear, but its vapor barrier is so noxious to insect's taste and olfactory senses that it discourages insect contact and biting. picaridin repels and deters mosquitoes so that mosquitoes keep a distance from the chemical and don't bite if they contact treated skin or clothing. When administered at the rate of $50 \mathrm{mg} / \mathrm{cm}^{2}$, the absence of dermal irritation on the back of human subjects was observed after the application of $20 \%$ of picaridincontaining products $[19,22]$. 


\subsubsection{Permethrin.}

Permethrin is classified as the class of synthetic chemical pyrethroids by composition and acts by touch or absorption against the target insect and also can serve as a mild repellent. Permethrin is a biocidifier to insects, the "cis-permethrin" shape has the greatest degree of insecticidal action (Figure 1). Permethrin terminates insects by making the nervous system hypersensitive to sensory stimuli. Neurotoxic symptoms, including hyperactivity, tremors, incoordination, paralysis, and hyperthermia, can occur in large doses. It may cause ocular and dermal irritation and it is a carcinogen [19,23]. Textiles embedded with permethrin are now used to provide the most effective protection against mosquito-borne diseases, along with other repellents such as DEET [19,24].<smiles>CC1(C)C(C=C(Cl)Cl)C1C(=O)OCc1cccc(Oc2ccccc2)c1</smiles><smiles>CCCN(CC)C(=O)c1cccc(C)c1</smiles>

Figure 1. Chemical structure of some mosquito repellent.

\subsection{Natural Repellents.}

Although a very strong synthetic repellent is available, eco-friendly methods for fabric are needed due to environmental side effects. Mosquito repellent qualities are shown by many natural products such as extracts from radicals, stems, leaves, blooms, fruits, and seeds of different plant species. The effectiveness of mosquito repellence, however, relies also on the quality of essential oil. Controlled release mechanism during its use so that it can last longer, and this is the major challenge for researchers to achieve that finish using natural mosquito repellent oil as an active ingredient as they are eco-friendly. Following are various natural mosquito repellents: citronella oil, castor oil, clove oil, eucalyptus oil, cedar oil, rosemary oil, peppermint oil, lemongrass oil, geranium oil, and Chrysanthemum [19].

\subsubsection{Chrysanthemum.}

Chrysanthemum is the best, despite the above described natural repellents. The notable characteristic of Chrysanthemum is that even when exposed to the climate, it has a long-term effect on mosquitoes. Various essential oils have been discovered as mosquito repellents in the recent past while being environmentally friendly and biodegradable. For example, the essential oil extracted from citronella has been found to possess effective repellent activity against the mosquito. Citronella oil possesses properties such as mood elevation during the depression, deodorizing, sterilizing, and bug-repelling [17,19]. 


\subsubsection{Neem.}

Neem, commonly considered a natural alternative to DEET, has been checked with variable outcomes for repellence against a variety of arthropods [17]. Several field studies have shown the very high efficacy of neem-based preparations [25-27]. Neem has a heavy smell that some people find irritating and hides the wearer's scent and can avoid the landing of insects. Neem components show many effects on insects, including mosquitoes, houseflies, cockroaches, and so on [28]. The EPA has not yet approved neem for use as a topical insect repellent because it has low dermal toxicity but can cause skin irritation, such as dermatitis when used undiluted. Neem oil is still not approved as an effective repellent because of the lack of credible tests, although it can confer some protection against biting mosquitoes [16].

\subsubsection{Eucalyptus Lemon.}

Eucalyptus lemon provides a possible natural repellent from the leaves of lemon. A pmenthano-3,8-diol (PMD) essential oil of lemon eucalyptus shows pesticidal properties and is an alternative to synthetic mosquito repellents. The mode of its operation may hide the environmental signals used to find the target by mosquitoes. It is assumed that PMD does not repel insects, but it only blocks or confuses the enticing signals that people produce so that mosquitoes can't find them. Pure PMD shows far superior repellent activity. It has also shown a remarkable ability to repel mosquitoes when compared to DEET. PMD is the only repellent dependent on plants that have proved its therapeutic usefulness in preventing malaria and are recognized as not posing a human health risk. But it should be noted that the oil of lemon eucalyptus does not have EPA registration for use as an insect repellent [29-31].

These essential oils may be added directly to the cotton textiles, emulsion application, or microencapsulation process $[19,32,33]$.

\section{Insect Repellent Finishing on Textile}

Many studies have been conducted in the last few years on insecticide repellents inserted into textiles and clothes designed for outdoor activities. Insect repellent textiles are normally prepared by appropriately finishing the fabric in its final form with repellent agents $[19,34]$. In this case. to fix the repellent agents on the fabrics, suitable binder compositions that can adhere to the fabrics and can simultaneously support the mosquito repellent agents should be used. Insect repellent textiles can also be produced before the preparation of materials by incorporating repellent agents into the fiber or yarn. In this case, insect repellents are applied during the spinning process of the fiber (mainly synthetic).

\subsection{Microencapsulation Method.}

Microencapsulation could be stated as the method of encompassing or encasing one substance inside another substance on a very small scale, producing capsules starting from less than a micron to more than a hundred microns in size. Microcapsules could also be spherically formed, with a continual wall, covering the core [19]. All three states of matter, solids, liquids, and gases, could also be microencapsulated. Alternatively, core materials could also be encapsulated to get released slowly through the capsule walls; it can be termed as controlled release mechanism or diffusion mechanism. 
4.1.1. Application of Microencapsulated Repellents by Pad-Dry-Cure Technique.

\subsubsection{Citronella oil is used in cotton finishing for mosquito-repellant.}

The cotton material has been processed using a microencapsulated citronella oil, which has a greater and more durable insect shield than materials with a repellent effect of over 90 percent over 3 weeks, with an ethanol solution of the essential oil sprayed $[17,35]$. Comparative studies of natural oils such as lemon oil, citronella oil, and tulsi oil and DEET used in fabric encapsulation techniques indicate that the effects of natural oil (especially lemongrass) are not all the same [17,36].

\subsubsection{Use of Andrographis paniculata herbal extract to repel the mosquito on cotton.}

The Andrographis paniculata strategy has proved to effectively impart the mosquito repellent effect on the cotton cloth to environmentally sustainable, like herbal extracts. An investigation was performed using a microencapsulation system to achieve the mosquitorepellency effect of up to $94 \%$, demonstrating mosquito-resistant solid behavior for up to 30 washes [17,37].

\subsection{Cyclodextrin applications.}

Cyclodextrins can form cyclic oligosaccharides with complex inclusion with many functional agents, such as insect repellents. The chemical structure of $\beta$-cyclodextrin was shown in Figure 2. They can be fixed to cotton surfaces by forming ester bonds with polycarboxylic acids such as 1,2,3,4-butane tetracarboxylic acid or citric acid. Insecticides such as permethrin and bio-allethrin were incorporated into the macromolecular structures of the modified cotton fabrics. The findings suggest that an improvement in the amount of insecticide in finished fabrics resulted in successful repellent activity against mosquitoes due to an increasing amount of cyclodextrin. Applicable advanced technology has been used to make limonene for cotton fabrics based on a previous fabric modification by grafting with monochlorotriasinyl- $\beta$-cyclodextrin (MCT- $\beta$-CD), where limonene has been integrated into the $\beta$-cyclodextrin cavity $[19,38]$.

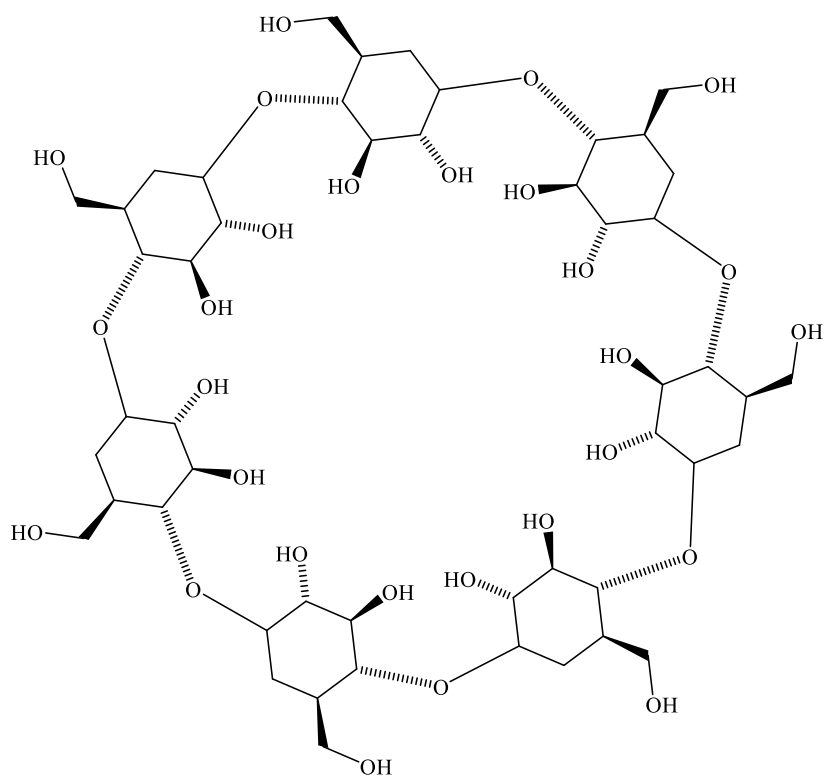

Figure 2. Structure and shape of $\beta$-cyclodextrin. 


\subsection{The Emulsion or Direct Application Method.}

The emulsion is made up of two immiscible liquids, one of which is a dispersed phase and the other of which is a continuous phase. In most textile applications, the emulsion is prepared as an oil-in-water form. The oil serves as the spread phase and the water serves as the continuous phase. The emulsifier is a substance that is used to prepare emulsions and gives them kinetic stability. Insect repellent properties are present in essential oils derived from the roots, stems, leaves, bulbs, fruits, and seeds of different plant species. Since essential oils are volatile, they evaporate readily at room temperature or as the temperature of the ambient atmosphere increases. However, the effectiveness of insect repellency is often influenced by the basic oil's composition. Chrysanthemum and citronella are two main natural sources that have insect-repelling effects. The oils were added to textiles, and the results revealed that essential oils of pine and guggul repel mosquitos better than rosewood oil when applied to a textile substrate $[19,39]$.

The insect repellent prallethrin was sprayed directly onto the cotton cloth. This was undertaken to increase the effectiveness of prallethrin as an insect repellent as well as its fabric retention. Via repeated washings and storage of the fabrics, the effectiveness and retention of prallethrin are assessed. The impregnation of the fabric with a solution containing prallethrin, a polymeric binder, and a crosslinking agent, or a surface coating of the fabric with a polymeric binder containing prallethrin were used to place prallethrin in the fabric. The results obtained with the treated fabrics show that increasing the concentration of prallethrin in the treated fabric within the range tested $(250-1500 \mathrm{mg} / \mathrm{m})$ increases the repellent and killing activity against mosquitoes. By raising the exposure time, the values of repellency improved as well. Prallethrin, permethrin, and eucalyptus oil were added to a cloth either directly or by a binder/crosslinker, and the insect repellent effectiveness was measured before and after washing. In the unwashed state, both repellents demonstrated good-to-excellent mosquito repellency $[19,40]$.

\subsection{The Sol-Gel Method.}

This method is a novel way to make solid materials out of small molecules. The technique includes transforming monomers into a colloidal solution (sol), which serves as a precursor for creating an interconnected network (gel) of isolated particles or network polymers. The sol-gel process is a low-cost, low-temperature procedure that allows for precise monitoring of the product's chemical composition. The sol-gel technique has recently been used to create an industrially viable method for manufacturing durable insecticidal textiles.

Permethrin was inserted into cotton fabrics using a silicon oxide nanocoating that was applied using standard padding and then cured. The influence of sol-gel process parameters such as solid silica content and the permethrin/tetraethyl orthosilicate (TEOS) ratio on insecticidal behavior and fabric properties was investigated. The nano sol coating produced textiles with a high mosquito repellent effect while maintaining their durability and softness. Furthermore, the insecticide content can be managed by merely applying the appropriate amount of insecticide to the coating bath. The washing fastness of textile fabric with a permethrin loading of $500 \mathrm{mg} / \mathrm{m}^{2}$ of fabric was tested, and the results showed that even after 50 washing cycles, the fabric had a strong insecticidal effect $[16,41]$. 


\section{Evaluation Methods}

At different stages, the efficacy of insect repellent finishes may be measured. Chemical experiments on a laboratory scale can be adequate if the concentration necessary to achieve efficacy is known. An attractant (human or artificial) and more mosquitoes are used in repellency testing [16].

\subsection{Arm-In-Cage Repellency Tests.}

Cage tests are a simple and inexpensive way to decide whether treated textiles are mosquito repellent. Volunteers cover a given region of their forearm with the treated textiles and then show it to hungry mosquitoes in a cage for this type of examination. The finish's efficacy is determined by the number of mosquitoes on the samples and the number of bites.

Test results are known by protective efficacy (PE), which is calculated by (mean number of mosquitoes landed on control arm - mean number of mosquitoes landed on test arm)/mean number of mosquitoes landed on the control arm [16].

\subsection{Novel Tests Without Humans.}

Insecticidal effect or the number of bites are considerations in conventional insect repellency studies. As they involve people, they are subject to large variation and besides are not human friendly. The Y-tube test is a novel test that does not include humans. This test employs a basic Y-form, with mosquitoes in a cage at the $\mathrm{Y}$-stem forms and either the bait or the bait + repellent at the Y-two form's sides. Air is circulated at a constant rate through the arms and across the stem. The mosquitoes are released into the stem after equalization so that they can approach the bait. The number of mosquitoes that enter each arm is counted, and the proportion of total mosquitoes entering the Y-tube for each arm is determined. Suppose a substance is a repellent to the mosquitoes. In that case, the percentage should be significantly lower in that arm than in the bait-only arm. Mosquitoes should ideally not land on the cloth at all, although if the landing is brief enough to avoid a bite, the product might be suitable [16].

\subsection{Excito-Repellency Tests.}

The World Health Organization (WHO) has created the first mosquito repellency test box made of plywood, intending to determine the excitation (irritability) of exposed mosquitoes after physical contact with insecticides $[16,42]$. This system was dubbed an excito-repellency test box after that. Several experiments have shown that most chemical compounds affect insect locomotor (movement) behavior, often resulting in profound excitation and premature movement away from treated surfaces or regions, a phenomenon known as avoidance behavior $[16,43]$. The mosquitoes' escape behavior was measured in this analysis, and reliable and repeatable findings were obtained $[16,44,45]$.

\subsection{Modified Excito Chamber Method.}

\subsubsection{Mosquito Collection.}

Before administering the experiments, the test mosquitos should be starved of blood and sugar. The mosquitoes were collected by a large flask $[21,46]$. 


\subsubsection{Repellency Behavioral Tests.}

In this test, two specially built excite repellency test chambers. Usually, a box, are used to assess repellency effectiveness. Before exposure, mosquitoes should be stripped of both food and water. The laboratory experiments can be repeated a few times. For each exposure chamber, the number of escaping specimens and those still within the chamber should be reported separately after each examination $[17,46]$. The following formula can be used to measure the percentage of mosquito repellency.

$\%$ Mosquito repellency $=(($ Number of specimens escaped + Number of specimens dead $) \times 100) \div$ Number of specimens exposed.

\section{Field Test}

The field test is the most significant proof of a handled textile's efficacy. It is particularly effective in areas where floodwater mosquitoes are prevalent $[17,47]$.

\section{Summary}

The textile industry has become well advanced in technology with value-added textile and clothing products. Insect repellent textiles assist in the prevention of vector-borne diseases such as malaria and dengue fever, which insects spread. Insect-resistant finishes can be added to textiles and garments in various ways, using chemicals or natural materials. The wet cleaning method can be used on curtains, upholstery materials, shoes, and carpet cloth, and other things. The efficacy of insect repellent finished fabric to provide protection can be measured and tested using standard methods. Future insect repellent finishes will focus on achieving efficient and long-lasting insect repellent properties while being environmentally sustainable.

\section{Funding}

This research received no external funding.

\section{Acknowledgments}

The authors are gratefully grateful to acknowledge the faculty of Applied Arts, Benha University, for the facilities provided. Thankful are also acknowledge to National Research Centre (NRC).

\section{Conflicts of Interest}

The authors declare no conflict of interest.

\section{References}

1. Mohamed, A.L.; Hassabo, A.G. Flame retardant of cellulosic materials and their composites. In Flame retardants, Visakh, P.M.; Arao, Y., Eds. Springer International Publishing. 2015; pp 247-314, http://dx.doi.org/10.1007/978-3-319-03467-6_10.

2. Nada, A.A.; Hassabo, A.G.; Mohamed, A.L.; Mounier, M.M.; Abou Zeid, N.Y. Liposomal microencapsulation of rodent-repelling agents onto jute burlaps: Assessment of cytotoxicity and rat behavioral test. JAPS 2016, 6, 142-150, http://doi.org/10.7324/JAPS.2016.60822.

3. Visakh, P.; Arao, Y. Flame retardants: Polymer blends, composites and nanocomposites. Publisher: Springer International Publishing, Switzerland 2015, https://doi.org/10.1007/978-3-319-03467-6. 
4. Abo-Shosha, M.H.; Nassar, F.A.; Haggag, K.; El-Sayed, Z.; Hassabo, A.G. Utilization of some fatty acid/peg condensates as emulsifiers in kerosene paste pigment printing. RJTA 2009, 13, 65-77.

5. El-Zawahry, M.M.; Hassabo, A.G.; Abdelghaffar, F.; Abdelghaffar, R.A.; Hakeim, O.A. Preparation and use of aqueous solutions magnetic chitosan / nanocellulose aerogels for the sorption of reactive black 5 . Biointerface Research in Applied Chemistry 2021, 11, $12380 \quad$ - 12402 , https://doi.org/10.33263/BRIAC114.1238012402.

6. El-Zawahry, M.M.; Abdelghaffar, F.; Abdelghaffar, R.A.; Hassabo, A.G. Equilibrium and kinetic models on the adsorption of reactive black 5 from aqueous solution using eichhornia crassipes/chitosan composite. Carbohydr. Polym. 2016, 136, 507-515, http://dx.doi.org/10.1016/j.carbpol.2015.09.071.

7. Ibrahim, N.A.; El-Sayed, Z.M.; Fahmy, H.M.; Hassabo, A.G.; Abo-Shosha, M.H. Perfume finishing of cotton / polyester fabric crosslinked with dmdheu in presence of some softeners. RJTA 2013, 17, 58-63, https://doi.org/10.1108/RJTA-17-04-2013-B007.

8. Mohamed, A.L.; El-Naggar, M.E.; Shaheen, T.I.; Hassabo, A.G. Novel nano polymeric system containing biosynthesized core shell silver/silica nanoparticles for functionalization of cellulosic based material. Microsys. Technol. 2016, 22, 979-992, http://doi.org/10.1007/s00542-015-2776-0.

9. Mohamed, A.L.; Er-Rafik, M.; Moller, M. Suitability of confocal raman microscopy for monitoring the penetration of pdms compounds into cotton fibres. Carbohydr. Polym. 2013, 96, 305-313, http://dx.doi.org/10.1016/j.carbpol.2013.03.087.

10. Mohamed, A.L.; Er-Rafik, M.; Moller, M. Supercritical carbon dioxide assisted silicon based finishing of cellulosic fabric: A novel approach. Carbohydr. Polym. 2013, 98, 1095-1107, http://dx.doi.org/10.1016/j.carbpol.2013.06.027.

11. Waly, A.I.; Abou-Zeid, N.Y.; Marie, M.M.; El-Sheikh, M.A.; Mohamed, A.L. Special finishing of cotton to impart flame-retardancy, easy care finishing and antimicrobial properties. RJTA 2009, 13, 10-26, https://doi.org/10.1108/RJTA-13-03-2009-B002.

12. Waly, A.I.; Marie, M.M.; Abou-Zeid, N.Y.; El-Sheikh, M.A.; Mohamed, A.L. Processes of dyeing, finishing and flame retardancy of cellulosic textiles in the presence of reactive tertiary amines. RJTA 2012, 16, 66 - 84, https://doi.org/10.1108/RJTA-16-03-2012-B007.

13. What Are the Harmful Effects of Insects? Available online: https://sciencing.com/what-are-the-harmfuleffects-of-insects-13406076.html (accessed on 15 May 2021).

14. Dai, X.; Jin, Z.; Tao, J. Study on comfort performance of seamless knitted fabric with mosquito-proof fiber. 2019 12th ISCID, Hangzhou, China, 14-15 December; Publisher: IEEE, New York, USA, 2019; 163-166, http://doi.org/10.1109/iscid.2019.00044.

15. Walker, N.F.; Nadjm, B.; Whitty, C.J.M. Malaria. Medicine 2014, 42, 52-58, https://doi.org/10.1016/j.mpmed.2017.10.012.

16. Paul, R. Functional finishes for textiles: Improving comfort, performance and protection, $1^{\text {st }}$ ed.; Publisher: Woodhead Publishing, Cambridge, UK, 2014; pp. 333-360, https://doi.org/10.1016/C2013-0-16373-8.

17. Agnihotri, A.; Wazed Ali, S.; Das, A.; Alagirusamy, R. Insect-repellent textiles using green and sustainable approaches. In The Impact and Prospects of Green Chemistry for Textile Technology; Ul-Islam, S., Butola, B.S. Eds.; Publisher: Woodhead Publishing, Cambridge, UK, 2019; pp. 307-325, http://doi.org/10.1016/b978-0-08-102491-1.00011-3.

18. Dickens, J.C.; Bohbot, J.D. Mini review: Mode of action of mosquito repellents. Pestic Biochem Physiol 2013, 106, 149-155, https://doi.org/10.1016/j.pestbp.2013.02.006.

19. Butola, B.S. Advances in functional and protective textiles, $1^{\text {st }}$ ed.; Publisher: Woodhead Publishing, Cambridge, UK, 2020; pp. 335-357, https://doi.org/10.1016/C2019-0-01192-2.

20. Shahba, A.F.; Halawa, O.; Ragei, M.; Hashen, M. Development of longer lasting insect repellenc cellulosic based curtain fabrics. Mater. Sci. Appl. 2011, 2, 200-208, https://doi.org/10.4236/msa.2011.23025.

21. Tseghai, G.B. Mosquito repellent finish of cotton fabric by extracting castor oil. Inter. J. Sci. Eng. Res. 2016, 7, 873-878.

22. Klun, J.A.; Khrimian, A.; Debboun, M. Repellent and deterrent effects of ss220, picaridin, and deet suppress human blood feeding by aedes aegypti, anopheles stephensi, and phlebotomus papatasi. J Med Entomol 2006, 43, 34-39, https://doi.org/10.1093/jmedent/43.1.34.

23. Drago, B.; Shah, N.S.; Shah, S.H. Acute permethrin neurotoxicity: Variable presentations, high index of suspicion. Toxicology reports 2014, 1, 1026-1028, https://doi.org/10.1016/j.toxrep.2014.09.007.

24. Freedman, D.O.; Weld, L.H.; Kozarsky, P.E.; Fisk, T.; Robins, R.; von Sonnenburg, F.; Keystone, J.S.; Pandey, P.; Cetron, M.S. Spectrum of disease and relation to place of exposure among ill returned travelers. N Engl J Med 2006, 354, 119-130, https://doi.org/10.1056/NEJMoa051331.

25. Caraballo, A.J. Mosquito repellent action of neemos. J. Am. Mosq. Control Assoc 2000, 16, 45-46.

26. Sharma, V.P., Ansari, M.A., Razdan, R.K. Mosquito repellent action of neem (Azadirachta indica) oil. $J$ Am Mosq Control Assoc 1993, 9, 359-360.

27. Singh, N., Mishra, A.K., Saxena, A., . Use of neem cream as a mosquito repellent in tribal areas of central india. Indian J Malario. 1996, 33, 99-102.

28. Schmatterer, H. Properties and potential of natural pesticides from the neem tree, Azadirachta indica. Annu Rev Entomol 1990, 35, 271-297, https://doi.org/10.1146/annurev.en.35.010190.001415. 
29. Hill, N.; Lenglet, A.; Arnez, A.; Carneiro, I. Plant based insect repellent and insecticide treated bed nets to protect against malaria in areas of early evening biting vectors: Double blind randomised placebo controlled clinical trial in the bolivian Amazon. BMJ 2007, 335, 1023, https://doi.org/10.1136/bmj.39356.574641.55.

30. Yuasa, Y.; Tsuruta, H.; Yuasa, Y. A practical and efficient synthesis of p-menthane-3, 8-diols. Org Proc Res Dev 2000, 4, 159-161, https://doi.org/10.1021/op9901036.

31. Repellents: Protection against mosquitoes, ticks, and other insects and arthropods. Available online: https://www.epa.gov/insect-repellents (accessed on 16 May 2021).

32. Purev, N.; Burgert, L.; Prichystal, P.; Hrdina, R.; Kühn, J.; Cerny, M.; Oyuntulkhuur, J. Dyeing of leather with microencapsulated acid dye. Color Technol 2013, 129, 412-417, https://doi.org/10.1111/cote.12054.

33. Teli, M.; Chavan, P.P. Application of gelatine based microcapsules containing mosquito repellent oils on cellulosic biopolymer. Journal of Bionanoscience 2016, 10, 390-395, https://doi.org/ 10.1166/jbns.2016.1396.

34. Gopalakrishnan, D. Mosquito repellent fabrics. Man-Made Textiles in India 2007, 50, 15-18.

35. Specos, M.M.M.; García, J.J.; Tornesello, J.; Marino, P., Della Vecchia, M.; Defain Tesoriero, M.V.; Hermida, L.G. Micro encapsulated citronella oil for mosquito repellent finish of cotton. Trans R Soc Trop Med Hyg 2010, 104, 653-658, https://doi.org/10.1016/j.trstmh.2010.06.004.

36. Thite, A.G.; Gudiyawar, M.Y.; Development of microencapsulated eco-friendly mosquito repellent cotton finished fabric by natural repellent oils. Int J Sci Technol Manag 2015, 04, 166-174.

37. Ramya, K.; Maheshwari, V. Development of eco-friendly mosquito repellent fabric finished with Andrographis paniculata plant extract. IJPPS 2014, 6, 115-117.

38. Hebeish, A.; Fouda, M.M.G.; Hamdy, I.A.; El-Sawy, S.M.; Abdel-Mohdy, F.A. Preparation of durable insect repellent cotton fabric: Limonene as insecticide. Carbohydrate Polymers 2008, 74, 268-273, https://doi.org/10.1016/j.carbpol.2008.02.013.

39. Jaipum, L., Saini, M. and Rangi, A. Development of herbal mosquito repellent textiles using essential oils of pine, guggul and rosewood. Colourage 2016, 63, 44-48.

40. Gulrajani, M.; Agarwal, A.; Lohia, C. Preparation of mosquito repellent fabrics. Asian Dyer 2007, 4, 5355.

41. Ardanuy, M.; Faccini, M.; Amantia, D.; Aubouy, L.; Borja, G. Preparation of durable insecticide cotton fabrics through sol-gel treatment with permethrin. Surface and coatings technology 2014, 239, 132-137, https://doi.org/10.1016/j.surfcoat.2013.11.031.

42. Rachou, R.G.; Moura-Lima, M.; Duret, J.P.; Kerr, J.A.; Experiences with the excito-repellency test boxmodel OPS. World Health Organization 1963, https://apps.who.int/iris/handle/10665/65090.

43. Kongmee, M.; Prabaripai, A.; Akratanakul, P.; Bangs, M.J.; Chareonviriyaphap, T. Behavioral responses of aedes aegypti (diptera: Culicidae) exposed to deltamethrin and possible implications for disease control. J Med Entomol 2004, 41, 1055-1063, https://doi.org/10.1603/0022-2585-41.6.1055.

44. Chareonviriyaphap, T.; Roberts, D.; Andre, R.G.; Harlan, H.; Manguin, S.; Bangs, M. Pesticide avoidance behavior in anopheles albimanus, a malaria vector in the americas. J Am Mosq Control Assoc 1997, 13, 171-183.

45. Roberts, D.R.; Chareonviriyaphap, T.; Harlan, H.H.; Hshieh, P. Methods of testing and analyzing excitorepellency responses of malaria vectors to insecticides. J Am Mosq Control Assoc 1997, 13, 13-17.

46. Anuar, A.A.; Yusof, N. Methods of imparting mosquito repellent agents and the assenting mosquito repellancy on textile. Fash Text 2016, 3, https://doi.org/10.1186/s40691-016-0064-y.

47. Kim, J.K.; Kang, C.S.; Lee, J.K.; Kim, Y.R.; Han, H.Y.; Yun. H.K. Evaluation of repellency effect of two natural aroma mosquito repellent compounds, citronella and citronellal. . Entomol. Res. 2007, 35, 117-120, https://doi.org/10.1111/j.1748-5967.2005.tb00146.x. 